\title{
The Short-Term Effect of Surgical Treatment for Stress Urinary Incontinence Using Sub Urethral Support Techniques on Sexual Function
}

\author{
Antonio C. Pinto, Fabio Baracat, Nelson D. Montellato, Anuar I. Mitre, Antonio M. Lucon, \\ Miguel Srougi
}

Division of Urology, University of Sao Paulo Medical School, Sao Paulo, SP, Brazil

\begin{abstract}
Objectives: To evaluate the impact of surgical treatment of stress urinary incontinence on the sexual function of women and to identify whether such treatment can improve their sexual function and overall quality of life.

Materials and Methods: 64 heterosexual women with such indication were studied using the Female Sexual Function Index (FSFI) questionnaire, modified by introducing one question to evaluate the impact of urine loss. This was applied preoperatively and six months after surgery.

Result: Among these 64 patients, $60.94 \%$ had regular sexual activity, while $39.06 \%$ did not. Among sexually active patients, $59 \%$ had urine loss during sexual intercourse and, of these, $87 \%$ had urine losses in half or more of sexual relations. There were no statistically significant differences in assessments of desire, arousal, lubrication, orgasm, satisfaction and pain, or in totaling the scores, between the preoperative period and six months after surgical treatment. However, the scores for urine losses during sexual intercourse were significantly better after the operation.

Conclusions: Analysis of the results allowed the following conclusions to be reached: Urine lost during sexual activity was frequent among patients with stress urinary incontinence. Suburethral support surgery did not jeopardize sexual activity. Patients cured of stress urinary incontinence did not present improvement in sexual function.
\end{abstract}

Key words: urinary incontinence, stress; prostheses and implants; female, sex disorders Int Braz J Urol. 2007; 33: 822-8

\section{INTRODUCTION}

Epidemiological studies have suggested that the same pathological processes and risk factors that are associated to male erectile dysfunction (age, hypertension, smoking, hypercholesterolemia and previous pelvic surgery) are also associated to female sexual dysfunction (FSD) (1).

Sexual dysfunction (SD) is highly prevalent in both sexes, ranging from $10 \%$ to $52 \%$ among males and from $25 \%$ to $63 \%$ among females. Data from the Massachusetts Male Aging Study (MMAS) has shown that $34.8 \%$ of men aged 40 to 70 years have moderate $\mathrm{SD}$, which is strongly related to age, associated diseases (diabetes, hypertension and hypercholesterolemia) and emotional state (1). Less is known about the epidemiological aspects of FSD (2).

Female urinary incontinence (UI) is highly prevalent. Diokno (1995) found prevalence ranging from $10 \%$ to $25 \%$ in a population within the age group 
from 15 to 64 years old. The numbers may increase if older populations are studied. It is worth emphasizing that, in the United States, dealing with UI has an annual cost of 10 billion dollars (3).

Although SD and UI both have high incidence, few studies have sought to correlate them aiming at assessing the impact of UI on women's sexual life. Likewise, there has been little study of the improvements that might be obtained, if any, after treatment for UI.

Considering the high prevalence of SUI in our environment, our objectives in the present study were to evaluate: The impact of UI on the sexual life of women with an indication for surgical treatment using suburethral support techniques (SST) and Whether the correction of this dysfunction might favor these patients' sexual lives, thereby causing an improvement in their quality of life.

\section{MATERIALS AND METHODS}

Sixty-four heterosexual women from the urogynecology outpatient clinic were sequentially studied between August 2001 and September 2002. All of them were indicated for treatment of SUI by means of SST. The patients' ages ranged from 33 to 86 years, with a mean of 56 years, standard deviation of 12.3 years and median of 55 years.

We chose to subjectively examine the sexual function of all the patients studied, by means of applying a modified version of the Female Sexual Function Index (FSFI) questionnaire, which was devised by UMDNJ Robert Wood Johnson Medical School, Piscataway, NJ; University of Tennessee, Memphis, TN; University of Washington, Seattle, WA; University of Texas, Austin, TX; and Columbia University School of Medicine, New York, NY (4). This questionnaire consists of 19 questions and assesses the domains of desire, arousal, lubrication, orgasm, satisfaction and pain symptoms. We added one question to this, with the aim of quantifying the impact of urine loss during sexual intercourse.

On the eve of the surgical procedure, the patients received detailed explanations about the study and authorization to consent was obtained.
Firstly, the patients were asked objectively about their basic disease, with the aim of characterizing the urine losses that they presented. They were also asked about previous surgical procedures that they had undergone, with emphasis on procedures with vaginal access. Next, the modified FSFI was applied. The patients were requested to respond spontaneously to the questionnaire and take as much time as needed to answer it, in a calm environment without anyone else present. In the event that doubts arose with regard to any item, the investigator was called to provide the clarifications needed.

Six months after the surgical procedure, the patients who had had any sexual activity were invited to attend the urogynecology outpatient clinic at a prearranged time. First of all, they were asked about how successful the procedure had been with regard to urine losses and about any complications that may have occurred. Following this, the modified FSFI was again applied, under the same conditions as adopted previously.

For the continuous quantitative variables, the analysis described was done by means of observing the minimum and maximum values and calculating the means, standard deviations and medians. For the category variables, absolute and relative frequencies were calculated. When it was necessary to verify whether there were associations between the category variables, the chi-squared association test was utilized, or the Fisher exact test if at least one expected frequency was less than five.

To verify the impact of the surgical procedure performed, by means of comparisons between the mean scores for the items of desire, arousal, lubrication, orgasm, satisfaction, pain and urine losses, the non-parametric Wilcoxon signs test was applied.

The significance level utilized for the tests was $5 \%$.

\section{RESULTS}

In accordance with the age distribution of the patients, they were subdivided into two groups. The first group included patients whose ages were less than or equal to 50 years and the second consisted of women whose ages were over 50 years (Table-1). 
Table 1 - Distribution of patients with and without sexual activity, by age group.

\begin{tabular}{lcccccc}
\hline Age (years) & Without & $\%$ & With & $\%$ & Total & $\%$ \\
\hline$\leq 50$ & 6 & 24 & 22 & 56.4 & 28 & 43.75 \\
$\geq 51$ & 19 & 76 & 17 & 43.6 & 36 & 56.75 \\
Total & 25 & 100 & 39 & 100 & 64 & 100 \\
\hline
\end{tabular}

Among the 64 patients who underwent surgical treatment for SUI using the SST, 39 patients (60.94\%) had had sexual activity during the preceding four weeks, while 25 patients (39.06\%) had not had sexual activity. The distribution by age group for the patients with and without sexual activity is shown in Table-1. Application of the chi-squared test to these two samples gave $\mathrm{p}=0.011$; therefore, age group had an influence on sexual activity (significant value).

Table 2 - Causes of absence of sexual activity.

\begin{tabular}{lll}
\hline Cause & N & \% \\
\hline Lack of partner & 11 & 44 \\
Lack of desire & 10 & 40 \\
Illness of patient & 1 & 4 \\
Illness of partner & 3 & 12 \\
Total & 25 & 100 \\
\hline
\end{tabular}

Among the patients without sexual activity, the reasons given for this abstinence were lack of partner; absence of sexual desire; partner with illness that impeded him from having sexual activity; and illness of the patient herself (Table-2). Only two (8\%) of the 25 patients without sexual activity presented scores of six or over on the sexual desire question, while the range found was from 2 to 10 .

Table- 3 shows the means, standard deviations and medians for the 39 patients with sexual activity, for all the domains evaluated. Of these patients with sexual activity, 23 (59\%) said they had urine losses during the sexual act, while $20(51 \%)$ presented urine losses on $50 \%$ or more of the occasions when they had sexual activity (scores of 3, 2 and 1) and 13 (33\%) had losses on all such occasions (score of 1).

Among the 39 patients who underwent treatment for SUI using SST, only one patient did not attend the outpatient clinic six months after the surgical procedure to answer the questionnaire again.

Table 3 - Scoring for the different questions among patients with sexual activity before the operation.

\begin{tabular}{|c|c|c|c|}
\hline & Mean & Standard Deviation & Median \\
\hline Desire & 5.82 & 1.78 & 6 \\
\hline Arousal & 13.74 & 3.41 & 13 \\
\hline Lubrication & 14.71 & 4.67 & 15 \\
\hline Orgasm & 8.68 & 3.92 & 9 \\
\hline Satisfaction & 9.89 & 3.74 & 9 \\
\hline Pain & 11 & 4.61 & 13.5 \\
\hline Losses & 3.34 & 1.74 & 4 \\
\hline Total & 67.08 & 12.78 & 67 \\
\hline
\end{tabular}


With regard to sexual desire, 10 patients (26.31\%) presented increases in their scores, 24 remained unchanged and four had decreases. With regard to arousal, lubrication, orgasm, satisfaction and pain, similar distributions were found, i.e. more than $60 \%$ of the patients kept the same scores, while $10 \%$ to $30 \%$ of the patients had upward or downward changes in their scores. With regard to urinary loss during sexual activity, 20 patients $(52.63 \%)$ presented an improvement, while 18 (47.37\%) maintained their scores. No patient mentioned any worsening of the urine loss during sexual activity after the operation (Table-4).

Table- 5 shows the mean preoperative and postoperative scores and significance levels after applying the non-parametric Wilcoxon signs test, which was utilized to compare the mean scores of the different domains of the FSFI. It could be seen that the items of arousal, lubrication, orgasm and totaling presented slight reductions, while desire, pain and urine losses had slight increases. However, none of these except for the domain of urine losses during the sexual act presented significance levels of less than 5\%.

\section{COMMENTS}

At the beginning of 1999, the National Health and Social Life Survey (NHSLS) published a study in the Journal of the American Medical Association (2) that showed that sexual problems were more frequent than had been imagined; $43 \%$ of American women presented $\mathrm{SD}$, a percentage that was higher than for men, whose rate was $31 \%$. These data concur with

Table 4-Change in scores for the different questions from before surgery to after surgery.

\begin{tabular}{lcccccccc}
\hline Variable & \multicolumn{2}{c}{ Higher } & \multicolumn{2}{c}{ Unchanged } & \multicolumn{2}{c}{ Lower } & \multicolumn{2}{c}{ Total } \\
& $\mathbf{N}$ & $\mathbf{\%}$ & $\mathbf{N}$ & $\mathbf{\%}$ & $\mathbf{N}$ & $\mathbf{\%}$ & $\mathbf{N}$ & $\%$ \\
\hline Desire & 10 & 26.31 & 24 & 63.16 & 4 & 10.53 & 38 & 100 \\
Arousal & 8 & 21.05 & 25 & 65.79 & 5 & 13.16 & 38 & 100 \\
Lubrication & 4 & 10.53 & 23 & 60.52 & 11 & 28.95 & 38 & 100 \\
Orgasm & 7 & 18.42 & 24 & 63.16 & 7 & 18.42 & 38 & 100 \\
Satisfaction & 5 & 13.16 & 25 & 65.79 & 8 & 21.05 & 38 & 100 \\
Pain & 7 & 18.42 & 24 & 63.16 & 7 & 18.42 & 38 & 100 \\
Losses & 20 & 52.63 & 18 & 47.37 & 0 & 0 & 38 & 100 \\
Total & 20 & 52.63 & 6 & 15.79 & 12 & 31.58 & 38 & 100 \\
\hline
\end{tabular}

Table 5 - Comparison between mean scores before and after surgery, with significance level.

\begin{tabular}{lccc}
\hline Variable & Before Surgery & After Surgery & p Value \\
\hline Desire & $5.82(1.78)$ & $6.08(2.20)$ & 0.265 \\
Arousal & $13.74(3.41)$ & $13.61(4.26)$ & 0.972 \\
Lubrication & $14.71(4.67)$ & $14.42(4.82)$ & 0.242 \\
Orgasm & $8.68(3.92)$ & $8.58(4.12)$ & 0.825 \\
Satisfaction & $9.89(3.74)$ & $9.53(4.07)$ & 0.420 \\
Pain & $11.00(4.61)$ & $11.29(3.86)$ & 0.706 \\
Losses & $3.34(1.74)$ & $4.82(0.83)$ & $<0.001$ \\
Total & $67.08(12.78)$ & $68.42(16.43)$ & 0.182 \\
\hline
\end{tabular}


the high incidence of women without sexual activity found in the present study, since $39.06 \%$ of the patients (29 women) were not having sexual relations. Despite the low number of women in the sample studied, the presence of women aged less than 50 years in this group and the fact that this was specifically a sample of women with SUI, it was observed that age had a significant influence on whether or not there was sexual activity. This result finds confirmation in the study by Diokno, with patients aged over 60 years: the latter study demonstrated that sexual activity diminishes with age and when the individual is single (5).

In the present study, patients explained their lack of sexual activity in different ways, but absence of desire was the principal factor that impeded sexual activity among these women, which can be demonstrated from the scoring for these patients. Thus, only two of these women $(8 \%)$ had scores of greater than or equal to 7), while 21 (84\%) presented scores of less than 4.

Out of the 20 patients without sexual activity that we managed to contact after a year of surgical procedure, $3(15 \%)$ returned to sexual activity. In two cases, this sexual activity retaking was associated to the fact of not presenting urinary losses to the efforts, demonstrating that urinary losses can decrease sexual desire, considering that both patients related such losses as the cause for the low desire for sexual activity.

Sutherst \& Brown evaluated the conjugal relations and sexual habits of 208 patients in a urinary incontinence clinic and observed that $43 \%$ of them said that urinary disorders had a negative effect on their sexual relations. According to these authors, women with vesicle instability had significantly greater incidence of SD than did women with genuine stress urinary incontinence (6).

A study by Iosif found that $20 \%$ of the women had diminished frequency of sexual activity and 5\% were completely inactive sexually, as a result of urine losses during coitus or during the night (7).

In a prospective study, Haase \& Skibsted reported that $35 \%$ of their patients had diminished libido in relation to the period prior to their urinary incontinence. Among such patients, 11 attributed the disorder to vaginal descensus or urine loss during the sexual act, and three just to the fear that such losses might occur. Twenty-three (42\%) complained of dyspareunia (8).

In the present study, 23 women (59\%) presented urine losses during sexual intercourse and, $20(86.96 \%)$ of them said they had losses on at least half of such occasions, while $13(56.72 \%)$ had urine loses on all occasions. Although this was not objectively asked about, it should be considered to be the preponderant factor in determining an unsatisfactory sexual life. The insecurity brought about by urine loss during day-today activities causes discontent and, with the intention of avoiding such losses, some activities are not done. Thus, what can be said about urine losses during intercourse? There is no doubt that it is a factor that must be taken into account when considering the low rates of desire, orgasm and satisfaction seen among preoperative patients. For this reason, when dealing with patients with UI, the negative impact that this has on female sexual life must not be forgotten. It is therefore appropriate to objectively probe patients about urine losses during the sexual act, as well as attempting to assess their impact.

Clark \& Romm evaluated the effects of UI on sexual function by means of a questionnaire, and found that $56 \%$ of their patients had already experienced urine losses during sexual activity. These rates reached $66 \%$ when the patients were asked about incontinence or urinary urge or frequency during the relations. These data, which are very similar to the findings of the present study, demonstrate the negative impact that urinary incontinence may have on the quality of life of patients with SUI (9).

Despite the high incidence of FSD and SUI, there are few studies that have sought to correlate the two diseases. It was found by Hilliges et al. (10) in 1995 that the more distal portions of the vagina have more nerve components when compared to the proximal proportions. These findings were similar with regard to the anterior and posterior walls; and the areas that commonly undergo incision during procedures to treat urine losses are richly innervated. Taking these findings into consideration, it must be emphasized that it is imperative to study sexual function after such procedures have been performed, with the aim of assessing their effects on FSD. 
Between the mean scores before and after the surgical procedure performed, it was observed that there were slight increases in the domains of desire and pain and the totaling of the scores, and a large increase in the item of urine loss during sexual intercourse, while for the variables of arousal, lubrication, orgasm and satisfaction there were slight decreases. Upon applying the statistical test, however, the significance level was not reached for any of them except for the variable of urine loss during sexual intercourse, which increased from 3.34 to 4.82 , which was very close to the maximum score of 5 for this variable. This result was already expected, given that the "gold standard" treatment for urinary incontinence today is the surgery that was performed (11).

The diversity of the results is probably the result of non-standardization of the studies, given that it was only in 1998 that the American Foundation of Urologic Disease (AFUD) defined and classified female sexual dysfunction (12).

Analysis of the literature with regard to the treatment of SUI and patients' sexual life after the surgical procedure has shown greater uniformity of results, despite the low number of published studies. Iosif (7) and Haase \& Skibsted (8) demonstrated an improvement in sexual activity and accredited the result to the greater satisfaction and self-esteem among their patients.

Recently, Walsh et al. (13) identified improvement in sexual function among their patients and stated that the solution for incontinence during intercourse was strongly associated with the improvement in sexual activity. Maaita et al. (14), in a similar study, concluded that this surgery would not have a negative effect on their patients' sexual lives.

The relationship between FSD and UI has reached such proportions today that Rogers et al. (15) have proposed that women with urinary incontinence or prolapse of pelvic organs behave differently from other populations studied previously from a sexual point of view. Thus, results obtained that would possibly be attributed to a series of factors such as age, for example, may be related to UI or genital prolapse. These authors even proposed a specific questionnaire for evaluating the impact of these diseases.
There is constant concern regarding the possibility of interfering in vaginal sensitivity, resulting from the fact that the principal site of innervation is the location for the incision in the surgical procedure for treating urinary incontinence using the suburethral support techniques. Nonetheless, the improvement in the patients' self-esteem produced by the absence of urine losses during the sexual act justifies the results, even if the improvements obtained in the patients of the present study were not significant. On the other hand, the worsening in sexual function found in some patients was related to complications in the procedures carried out, such as maintenance of urine losses, prolonged urine retention, urgency, etc. The SST for treating SUI is safe and does not worsen patients' sexual activity, but new studies should be conducted, using objective measurements of sexual function if possible, with the aim of confirming the results obtained.

This work will need to be taken to greater depth in order to obtain objective assessments of female sexual function, perhaps with quantification of the free nerve terminations in the anterior vaginal wall before and after the operation. This would be a way of assessing whether the SST could cause damage to female sexual function, with the attempt to identify, which patients might present worsening of this function after the operation, and whether the type of suburethral support utilized might interfere with the result obtained.

\section{CONCLUSIONS}

Analysis of the results regarding the sexual function of the women with SUI who underwent surgical treatment using SST allowed the following conclusions to be reached: age had an influence on sexual activity; urine loss during sexual activity was frequent among patients with SUI. The surgery presented cure rates of more than $90 \%$ for urine losses during the sexual act and did not jeopardize the patients' sexual activity; the improvement in sexual function, when it occurred, was subjectively related to increased sexual desire and not the reduction in urine losses during sexual relations after the surgical treatment, and the patients cured of SUI did not present improvement in relation to sexual function. 


\section{CONFLICT OF INTEREST}

None declared.

\section{REFERENCES}

1. Berman JR, Goldstein I: Female sexual dysfunction. Urol Clin North Am. 2001; 28: 405-16.

2. Laumann EO, Paik A, Rosen RC: Sexual dysfunction in the United States: prevalence and predictors. JAMA. 1999; 281: 537-44. Erratum in: JAMA 1999; 281: 1174.

3. Diokno AC: Epidemiology and psychosocial aspects of incontinence. Urol Clin North Am. 1995; 22: 481-5.

4. Rosen R, Brown C, Heiman J, Leiblum S, Meston C, Shabsigh R, et al.: The Female Sexual Function Index (FSFI): a multidimensional self-report instrument for the assessment of female sexual function. J Sex Marital Ther. 2000; 26: 191-208.

5. Diokno AC, Brown MB, Herzog AR: Sexual function in the elderly. Arch Intern Med 1990; 150: 197-200.

6. Sutherst J, Brown M: Sexual dysfunction associated with urinary incontinence. Urol Int. 1980; 35: 414-6.

7. Iosif CS: Sexual function after colpo-urethrocystopexy in middle-aged women. Urol Int. 1988; 43: 231-3.

8. Haase P, Skibsted L: Influence of operations for stress incontinence and/or genital descensus on sexual life. Acta Obstet Gynecol Scand. 1988; 67: 659-61.
9. Clark A, Romm J: Effect of urinary incontinence on sexual activity in women. J Reprod Med. 1993; 38: 67983.

10. Hilliges M, Falconer C, Ekman-Ordeberg G, Johansson $\mathrm{O}$ : Innervation of the human vaginal mucosa as revealed by PGP 9.5 immunohistochemistry. Acta Anat (Basel). 1995; 153: 119-26.

11. BARACAT F: Tratamento cirúrgico da Incontinência urinária de esforço pela técnica de "sling" aponeurótico. Tese(doutorado) - Faculdade de Medicina da Universidade de São Paulo, São Paulo. 2000; pp. 1-106.

12. Basson R, Berman J, Burnett A, Derogatis L, Ferguson $\mathrm{D}$, Fourcroy J, et al.: Report of the international consensus development conference on female sexual dysfunction: definitions and classifications. J Urol. 2000; 163: 888-93.

13. Walsh IK, Donnellan SM, Stone AR: The effect of pubovaginal sling surgery on female sexual function. 97th Annual Meeting, Orlando, USA, 2002. J. Urol. 2002; 163: (Supplement) 74-4.

14. Maaita M, Bhaumik J, Davies AE: Sexual function after using tension-free vaginal tape for the surgical treatment of genuine stress incontinence. BJU Int. 2002; 90:540-3.

15. Rogers RG, Kammerer-Doak D, Villarreal A, Coates K, Qualls C: A new instrument to measure sexual function in women with urinary incontinence or pelvic organ prolapse. Am J Obstet Gynecol. 2001; 184: 552-8.

Correspondence address:

Dr. Antonio Cardoso Pinto

Rua Cero Corá 1917 B

São Paulo,SP, 05061-350, Brazil

E-mail: antonio.cardoso@ sbu.org.br 